Новые возможности триметазидина МВ в лечении

ишемической болезни сердца в условиях реальной клинической практики. Результаты Российского многоцентрового, рандомизированного исследования ПЕРСПЕКТИВА (часть II)

\author{
М.Г. Бубнова ${ }^{1 *}$, А.М. Аронов ${ }^{1}$, Р.Г. Оганов Р.Г. ${ }^{1}$, О.Г. Рудоманов ${ }^{2}$ (от имени участников \\ исследования) $* *$
}

${ }^{1}$ ФГУ Государственный научно-исследовательский Центр профилактической медицины

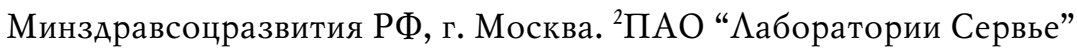

\title{
New potential of Trimetazidine MB for coronary heart disease treatment in the real-world clinical practice: results of the Russian multi-centre randomised study PERSPECTIVE (Part II)
}

\author{
M.G. Bubnova ${ }^{1 *}$, D.M. Aronov ${ }^{1}$, R.G. Oganov ${ }^{1}$, O.G. Rudomanov ${ }^{2}$ (on behalf of the Study \\ Group)**
}

1- State Research Centre for Preventive Medicine, Moscow; ${ }^{2}$ - Servier Laboratories

\begin{abstract}
Цель. В рамках клинической части Российского многоцентрового, рандомизированного исследования оценить пользу и безопасность включения триметазидина МВ в традиционную схему ведения больных стабильной стенокардией (СтСт) для оптимизации лечения на амбулаторно-поликлиническом этапе и повышения приверженности лечению.

Материал и методы. В исследование был включен 981 больной СтСт II и III функционального класса (ФК) в сочетании с сопутствующими заболеваниями и синдромами - хронической сердечной недостаточностью (ХСН), сахарным диабетом 2 типа (СД-2), хроническим обструктивным заболеванием легких (ХОБЛ) курильщика. Всех больных распределяли в две группы: I группа (n=838) - больные, получавшие триметазидин МВ в дозе 70 мг/сут, разделенной на два приема, дополнительно к стандартной терапии; II группа (контроль) $(\mathrm{n}=143)$ - больные, находившиеся на стандартной терапии. Общая продолжительность лечения и наблюдения составила -12 мес.

Результаты. В I группе отмечалось достоверное сокращение эпизодов стенокардии в нед на $42 \%$ от исходного, $(\mathrm{p}<0,0001)$ через 2 мес и $70 \%$ через 12 мес от исходного, $(\mathrm{p}<0,0001)$, а также количество приема таблеток нитроглицерина (Нтг) от $41 \%$ ( $<0,0001)$ до $68 \%(\mathrm{p}<0,0001)$, соответственно. Во II группе снижение эпизодов стенокардии и количества приема Нтг достоверно уменьшалось только к 6 мес и было менее выраженным. Это привело в I группе к увеличению в 7 раз числа больных с I ФК и сокращению в 1,8 раза с III ФК, тогда как в группе контроля видимых положительных изменений в распределении пациентов по ФК стенокардии не произошло. В І группе отмечено повышение фракции выброса левого желудочка на 2,4 \% (p<0,001), уменьшение толщины межжелудочковой перегородки на 4,2\% $(\mathrm{p}<0,01)$ и задней стенки ЛЖ на $3,5 \%$ ( $<0,01)$. Во II группе динамики вышеперечисленных показателей не отмечено. Через 12 мес из I группы в 2 раза меньше пациентов, чем во II группе было госпитализировано в связи с ухудшением клинического состояния и нуждалось в группе инвалидности.

Заключение. Результаты Российского исследования ПЕРСПЕКТИВА продемонстрировали высокую клиническую эффективность и безопасность терапии триметазидином МВ в комплексе с оптимальной стандартной терапией при СтСт, сочетающейся с ХСН, СД-2 или ХОБЛ, дающие основания для более активного применения метаболической терапии в реальной практике врача.
\end{abstract}

Ключевые слова: ишемическая болезнь сердца, стабильная стенокардия, триметазидин МВ.

\footnotetext{
(с)Коллектив авторов, 2011

e-mail mbubnova@gnicpm.ru
}

[Бубнова М.Г. (*контактное лицо) - проф., рук. отд. реабилитации и вторичной профилактики сочетанной патологии и лаборатории профилактики атеросклероза и тромбоза ГНИЦПМ; Аронов Д.М. - проф., рук. лаб. кардиолог. реабилитации отд.реабилитации и вторичной профилактики сочетанной патологии ГНИЦПМ; Оганов Р.Г. - проф., академик РАМН, ГНИЦПМ; Рудоманов О.Г. - сотрудник ПАО “Лаборатории Сервье".]. 
Aim. As a clinical part of the Russian multi-centre randomised study, to assess the clinical benefits and safety of adding Trimetazidine MB to the standard treatment scheme in patients with stable angina (SA), in order to optimise their ambulatory therapy and improve their compliance.

Material and methods. The study included 981 patients with Functional Class (FC) II-III SA and various concomitant diseases and syndromes, such as chronic heart failure (CHF), Type 2 diabetes mellitus (DM-2), or chronic obstructive pulmonary disease (COPD) in smokers. All participants were divided into two groups: Group I $(n=838)$ received standard therapy plus trimetazidine MB $(70 \mathrm{mg} / \mathrm{d}$, twice a day), while Group II $(n=143)$ received standard therapy only. The treatment and follow-up phases lasted for 12 months.

Results. In Group I, the weekly number of angina attacks decreased by $42 \%$ from the baseline at one month $(p<0,0001)$, and by $70 \%$ at 12 months $(p<0,0001)$. The number of nitroglycerin (NTG) tablets taken decreased, respectively, by $41 \%(p<0,0001)$ and $68 \%(p<0,0001)$. In Group II, the decrease in angina attack number and NTG tablet number was significant only at 6 months and was less pronounced than in Group I. Therefore, in Group I, the number of patients with FC I increased by 7 times, while the number of FC III patients decreased by 1,8 times. No marked FC dynamics was observed in Group II. In Group I, left ventricular ejection fraction (LVEF) increased by 2,4\% $(p<0,001)$, while interventricular septum and LV posterior wall thickness decreased, respectively, by $4,2 \%(p<0,01)$ and 3,5\% $(p<0,01)$. These parameters, however, did not change substantially in Group II patients. At 12 months, the number of patients hospitalised due to clinical decompensation, or becoming disable, was twice as high in Group II as in Group I.

Conclusion. The Russian "PERSPECTIVE" Study results demonstrated high clinical effectiveness and safety of Trimetazidine MB therapy, combined with standard treatment, in SA patients with CHF, DM-2, and COPD. Therefore, metabolic therapy could be more widely used in the real-world clinical settings.

Key words: Coronary heart disease, stable angina, trimetazidine MB.

Ишемическая болезнь сердца (ИБС) - ведущая причина инвалидизации и высокой преждевременной смертности трудоспособного населения России [1]. Основным клиническим проявлением хронической ИБС является стенокардия. Результаты эпидемиологической части Российского исследования "ПЕРСПЕКТИВА" (Перспектива антиангинальной тЕрапии в РосСии. Предуктал МВ в комплЕксной вторичной профилаКтике у пациенТов с ИБС и сопутствующими заболевАниями) продемонстрировали, что к национальным особенностям когорты пациентов со стабильной стенокардией (СтСт), можно отнести преобладание более тяжелых (II и III) функциональных классов (ФК) стенокардии на фоне выраженного многососудистого атеросклеротического поражения [2]. Напротив, в популяции Европейских больных СтСт распространены I и II ФК стенокардии [3].

Одновременно нельзя не заметить те положительные тенденции в лечении больных СтСт, которые появились с момента окончания в 2001г международного исследования ATP (Angina Treatment Patterns Survey), в котором участвовали 9 стран Европы, в т. ч. 18 центров из России [4]. В эпидемиологической части исследования ПЕРСПЕКТИВА, проводимой в 2010г с участием 2768 больных СтСт, отмечалось сокращение количества пациентов c $\geq 10$ и приступами СтСт в нед до $17,7 \%$ vs $35,2 \%$ в исследовании ATP-Survey [2]. При этом каждый второй пациент $(58,3 \%)$ в исследовании ПЕРСПЕКТИВА за последний мес имел $<5$ приступов СтСт в нед. Заметно уменьшилось среднее количество таблеток нитроглицерина (Нтг) в нед, принятых для купирования приступа стенокардии, с 10,3 в исследование АТР до 6,21 в исследовании ПЕРСПЕКТИВА. В 2010г по частоте эпизодов сте- нокардии и приему таблеток Нтг больной СтСт в России приблизился к характеристике пациента из Европы, хотя и десятилетней давности [2].

С одной стороны, наметившаяся позитивная тенденция обусловлена повышением приверженности врачей Национальным рекомендациям: по данным исследования ПЕРСПЕКТИВА $88,8 \%$ врачей в своей клинической практике придерживаются национальных рекомендаций и каждый третий меняет тактику ведения больного СтСт после ознакомления с рекомендациями. С другой стороны, в 2010г согласно исследованию ПЕРСПЕКТИВА произошли положительные изменения в структуре назначения лекарственных средств больным СтСт относительно данных 2001г в исследовании АТР: соответственно, $\beta$-адреноблокаторы ( $\beta$-АБ) принимали 78,5 \% пациентов (vs 67,8 \%), ингибиторы ангиотензинпревращающего фермента (ИАПФ) - 74,7 \% (vs $77,1 \%$ ), блокаторы рецепторов к ангиотензину II (БРА) $-9,5 \%$ (vs 0,24 \%), антагонисты кальция (AK) - 31,3\% (vs 35,6 \%), гиполипидемические препараты $-72,7$ \% (vs 17,1 \%) и ангиагреганты $89,8 \%$ (vs $82,7 \%$ ). На фоне такой комплексной терапии (68,5\% принимали $\geq 2$ антиангинальных препарата) в исследовании ПЕРСПЕКТИВА зафиксировано уменьшение назначения нитропрепаратов до 53,3 \% (в АТР 87,5 \%) без какоголибо ухудшения клинического течения стенокардии. Напротив, течение СтСт в определенной степени улучшилось, чему также способствовало усиление основной терапии больных СтСт метаболическим цитопротектором - триметазидином, который принимали 33,2 \% от всех включенных в эпидемиологическую часть исследования ПЕРСПЕКТИВА (vs 23,9 \% в АТР). 
Включение триметазидина модифицированного высвобождения (Предуктала МВ, Лаборатории Сервье, Франция) в основную терапию больных ИБС в исследовании ПЕРСПЕКТИВА - у каждого третьего при СТСт и у каждого второго после перенесенного инфаркта миокарда (ИМ) присутствует реальное отражение лучшего понимания практическими врачами необходимости метаболической терапии при ИБС и признание ее значимой антиангинальной эффективности для пациента. Согласно современным рекомендациям триметазидин МВ (Предуктал МВ) показан к назначению больным СтСт на любом этапе вторичной профилактики как для усиления антиангинальной эффективности гемодинамически активных препаратов ( $\beta$-АБ, АК или нитратов), так и в качестве альтернативы им при непереносимости или противопоказаниях к применению [1,5].

В то же время, очевидно, что антиангинальная терапия больных СтСт на современном этапе нуждается в дальнейшей качественной модификации, направленной на последующее сокращение количества приступов стенокардии, перевод больных в разряд более легкого по тяжести ФК (в I и II) стенокардии, улучшение их качества жизни (КЖ) и прогноза.

В клинической части Российского исследования ПЕРСПЕКТИВА ставилась цель оценить клиническую пользу и безопасность включения триметазидина МВ в традиционную схему ведения больных СтСт с сопутствующими заболеваниями и синдромами для оптимизации их лечения на амбулаторно-поликлиническом этапе и повышения приверженности пациентов лечению.

\section{Материалы и методы}

В клиническую часть исследования ПЕРСПЕКТИВА был включен 981 больной СтСт в сочетании с сопутствующими заболеваниями и синдромами - хронической сердечной недостаточностью $(\mathrm{XCH})$, сахарным диабетом 2 типа (СД-2), хроническим обструктивным заболеванием легких (ХОБЛ) курильщика. Исследование было открытым, многоцентровым, рандомизированным, контролируемым в параллельных группах.

Критерии включения в исследование:

- мужчины и женщины в возрасте 30-65 лет;

- ИБС, подтвержденная любым из нижеследующего: ИМ в анамнезе, и/или коронарной ангиографией, и/или перенесенными операциями аортокоронарного шунтирования (АКШ), транслюминальной баллонной ангиопластики (ТЛБ АП), стентированием, а также с положительными результатами нагрузочных тестов, включая изотопную сцинтиграфию, с типичными для ишемии миокарда;

- СтСт II или III ФК согласно классификации Канадской ассоциации кардиологов, причем диагноз должен быть поставлен не менее чем за 3 мес до включения;

- наличие одного из перечисленных сопутствующих заболеваний или синдромов:
- ХCH > I ФК по классификации Нью-йоркской ассоциации сердца (NYHA) - фракция выброса левого желудочка (ФВЛЖ) < $40 \%$;

- СД-2 в стадии субкомпенсации по углеводному обмену;

- ХОБЛ курильщика (пациент курит > 10 лет и $>10$ сигарет в день);

- подписание информированного согласия на участие в исследовании.

Критерии исключения из исследования:

- стенокардия IV ФК;

- нестабильная стенокардия, ИМ, ТЛБАП, стентирование, операция АКШ, транзиторная ишемическая атака, мозговой инсульт в предшествующие 3 мес перед включением;

- выраженная ХСН с ФВ ЛЖ $<40 \%$

- СД-1 любого течения и СД-2 тяжелого течения;

- стойкое повышение систолического артериального давления (САД) > 180 мм.рт.ст. и/или диастолического АД (ДАД) $>110$ мм.рт.ст. на фоне антигипертензивной терапии (АГТ);

- женщины в период беременности или лактации;

- повышенная чувствительность к триметазидину (со слов пациента)

- лечение триметазидином в течение последнего мес до включения в исследование;

- пациенты, которые, возможно, не будут выполнять предписаний врача;

- участие в других исследованиях в последние 3 мес перед включением.

Все больные, соответствующие критериям включения/исключения, распределялись в две группы:

I группа (n=838) - больные, получавшие триметазидин МВ (Предуктал МВ) в дозе 70 мг/сут, разделенной на 2 приема, дополнительно к стандартной терапии;

II группа (контроль) $(\mathrm{n}=143)$ - больные, находившиеся на стандартной терапии.

Во время исследования было разрешено использовать любую антиангинальную терапию (нитраты пролонгированного действия, $\beta$-АБ, АК), кроме триметазидина MB, любую иную сердечно-сосудистую терапию, а также любую терапию сопутствующих заболеваний и синдромов, которые имели место у пациента.

Критериями преждевременного прекращения исследования служили: отказ пациента от участия в исследовании и/или появление нежелательных явлений (НЯ), которые вынуждали врача к отмене препарата.

План обследования пациента включал: сбор анамнеза, антропометрические данные - рост, вес с вычис-

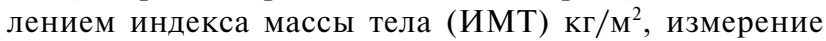
офисного уровня АД, частоты сердечных сокращений (ЧСС). Из инструментальных методов исследования больным выполнялись электокардиография (ЭКГ) в 12 отведениях, эхокардиография (ЭхоКГ) с определением ФВ ЛЖ сердца по методу Симпсона. Исследовали липидный спектр крови с определением (в ммоль/л) общего холестерина (ХС), триглицеридов (ТГ), ХС липопротеидов высокой плотности (ЛВП) и вычисление ХC липопротеидов низкой плотности (ЛНП) по формуле Friedwald WT. Осуществляли контроль за общим анализом крови, печеночными ферментами - аланинаминотрансферазой (АЛТ) и аспартатаминотрансферазой (АСТ), содержанием глюкозы крови. 
Бубнова М.Г., ... Триметазидин МВ в лечении ИБС: исследование ПЕРСПЕКТИВА...

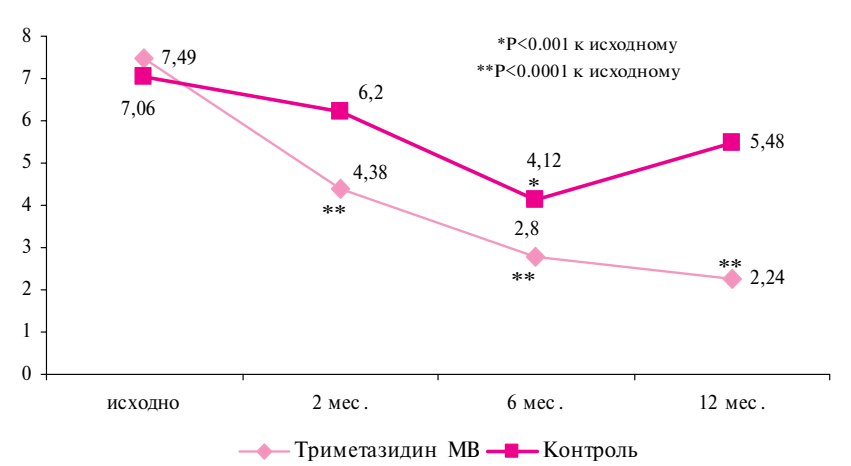

Puc.1 Динамика количества приступов стенокардии в нед в течение 12 мес лечения и наблюдения за больными СтСт (исследование ПЕРСПЕКТИВА).

Оценивали эффективность и переносимость лечения врачом и больным по четырем градациям: от “отлично” до “плохо”. В ходе исследования пациенты заполняли дневник самоконтроля приступов стенокардии и приема таблеток Нтг для купирования приступов или их профилактики.

Больные обеих групп приходили на визит к врачу через 2, 6 и 12 мес. Общая продолжительность лечения и наблюдения составила -12 мес.

При статистической обработке результатов использовали компьютерную программу SAS (версия 6.12). Применяли как стандартные методы описательной статистики (вычисление средних, стандартных отклонений, квинтилей и ранговых статистик и т. д.), так и известные критерии значимости $\left(\chi^{2}, \mathrm{t}\right.$-критерий Стьюдента, F-критерий Фишера). Непрерывные величины представлены в виде $\mathrm{M} \pm \mathrm{SD}$. Были использованы методы аналитической статистики: дисперсионноковариационный анализ в версии процедуры SAS PROC GLM (обобщенный линейный анализ. Статистический анализ был выполнен к.ф-м.н.Деевым А.Д (ГНИЦ ПМ).

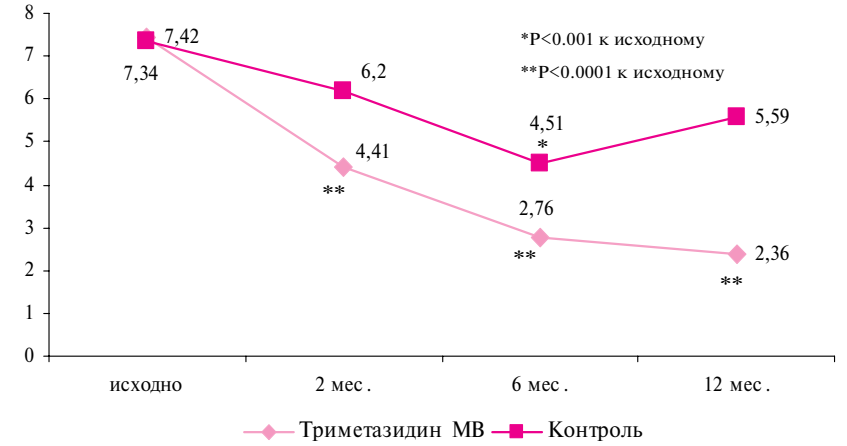

Puc.2 Динамика количества принимаемых таблеток Нтг в нед в течение 12 мес лечения и наблюдения за больными СтСт (исследование ПЕРСПЕКТИВА).

\section{Результаты}

Общая клиническая характеристика больных

Больные двух групп не различались по основным характеристикам: возрасту, частоте артериальной гипертонии (АГ), ХСН, СД-2, степени ожирения (Ож) (таблица 1). Практически половину включенных в исследование больных составляли женщины (I группа- 50 \% и II группа - 46,1 \%).

Длительность существования СтСт у больных I и II групп была: < 5 лет у 32,2 \% и $31 \%$ больных; 5-10 лет - у 46,8 \% и 44,2\%; > 10 лет - у $21 \%$ и $24,8 \%$, соответственно. Между группами не было различий по количеству приступов стенокардии в нед и ФК (каждый третий пациент имел III ФК стенокардии) (таблица 1). Практически каждый третий больной к моменту включения в исследование перенес ИМ.

В качестве стандартной терапии больные СтСт двух групп принимали антиагреганты, $\beta$-АБ, ИАПФ, нитраты пролонгированного действия, АК и диуре-

Характеристика больных СтСт с сопутствующими

Таблица 1 заболеваниями и симптомами (исследование ПЕРСПЕКТИВА)

\begin{tabular}{llll}
\hline Показатели & $\begin{array}{l}\text { I группа } \\
(\mathrm{n}=838)\end{array}$ & $\begin{array}{l}\text { II группа } \\
(\mathrm{n}=143)\end{array}$ & $\begin{array}{l}\text { Достоверность } \\
(\mathrm{p})\end{array}$ \\
\hline Возраст, лет & $56,8 \pm 0,2$ & $56,4 \pm 0,5$ & нд \\
Мужчины, (\%) & 50 & 53,9 & нд \\
АГ, $(\%)$ & 93,5 & 93,6 & нд \\
ХСН, (\%) & 84,5 & 83,3 & нд \\
ИМ в анамнезе, (\%) & 30,4 & 27,3 & нд \\
ФК стенокардии, (\%) & & & нд \\
ІІ & 69,3 & 70,6 & нд \\
ІІІ & 30,7 & 29,4 & нд \\
Количество приступов стенокардии в нед. & $7,49 \pm 0,28$ & $7,06 \pm 0,59$ & нд \\
Количество приема Нтг в нед. & $7,42 \pm 0,30$ & $7,34 \pm 0,74$ & нд \\
СД-2, (\%) & $33,4(268)$ & $22,1(30)$ & нд \\
ИМТ, кг/м & $29,7 \pm 0,2$ & $29,1 \pm 0,4$ & нд \\
САД, мм рт.ст. & $143,8 \pm 0,6$ & $146,0 \pm 1,3$ & нд \\
ДАД, мм рт.ст. & $87,8 \pm 0,3$ & $88,8 \pm 0,7$ & нд \\
ЧСС, уд/мин. & $73,5 \pm 0,3$ & $73,7 \pm 0,8$ & \\
\hline
\end{tabular}

Примечание: нд - недостоверно. 
тики (Д). Между группами достоверные различия отсутствовали.

Больные обеих групп не различались по уровню АД и величине ЧСС (таблица 1). Обращает на себя внимание наличие $А Г$ у большинства пациентов. При этом средний уровень САД и средняя величина ЧСС, несмотря на проводимую терапию (95,6\% больных в I группе и 94,4 \% больных II группы получали $\geq 3$ препаратов) превышали рекомендуемые целевые значения данных показателей. Это также могло поддерживать большую частоту приступов стенокардии у больных на момент включения в исследование: в I группе $-7,49 \pm 0,28$ приступов в нед и во II группе $-7,06 \pm 0,59$ приступов в нед.

\section{Оценка антиангинальной эффективности триметазидина МB}

Добавление триметазидина МВ к стандартной терапии больных СтСт (І группа) привело к достоверному $(\mathrm{p}<0,0001)$ сокращению количества приступов стенокардии в нед через 2 мес на $42 \%$ (рисунок 1). К 6 мес произошло заметное усиление антиангинального эффекта препарата - уменьшение количества приступов стенокардии в неделю составило $63 \%(\mathrm{p}<0,0001)$ K 12 мес лечения сокращение частоты приступов стенокардии в нед стало еще более выраженным - на $70 \%$ от исходного $(\mathrm{p}<0,0001)$. Это наглядно подтверждает важность длительного приема триметазидина МВ больными СтСт.

В группе контроля, находившейся исключительно на стандартной терапии, достоверное снижение количества приступов стенокардии у больных СтСт отмечалось только к 6 мес, и оно было меньше в 1,5 раза, всего на $42 \%,(\mathrm{p}<0,001)$, чем на триметазидине МВ (рисунок 1). Очевидно, одной из причин имевшейся положительной динамики по сокращению эпизодов стенокардии в контрольной группе к 6 мес явились контроль состояния пациента со стороны врача и повышение его приверженности терапии. В последующий период наблюдения (6-12 мес), когда пациенты не обращались к врачу, количество эпизодов стенокардии у них возвращалось к исходной величине. С другой стороны, нельзя исключить вероятность развития толерантности к нитратам, которые принимали пациенты.

В группе больных, принимавших триметазидин МВ в составе стандартной терапии, наблюдалось достоверное снижение количества принимаемых таблеток Нтг в нед ко 2 мес на $41 \%(\mathrm{p}<0,0001)$ с последующим их сокращением к 6 мес до $63 \%(\mathrm{p}<0,0001)$ и к 12 мес до $68 \%(\mathrm{p}<0,0001)$ от исходного (рисунок 2). Это подтверждает пользу длительного назначения триметазидина МВ больным СтСт для улучшения течения ИБС и КЖ.

В группе контроля достоверное сокращение количества принимаемых таблеток Нтг на $39 \%$
( $<<0,001)$ обнаружено только к 6-му месяцу, однако, это в 1,6 раза меньше, чем у принимавших триметазидин МВ (рисунок 2). В тоже время в период с 6 до 12 мес., в этой группе больных количество таблеток Нтг, принимаемых для купирования приступа стенокардии, возвращалось к исходному значению в отличие от группы больных, получавших триметазидин МВ.

В результате 12-месячного комплексного лечения больных СтСт, включающего триметазидин МВ, произошло существенное улучшение ФК стенокардии: количество больных с I ФК увеличилось в 7 раз, а количество больных с ІІІ ФК уменьшилось в 1,8 раза. В противоположность этому, в группе контроля видимых положительных изменений в распределении пациентов по ФК стенокардии не произошло.

\section{Оценка динамики уровней АД, ЧСС и ЭКГ}

В процессе наблюдения за больными на всех визитах оценивали ИМТ: его величина оставалась стабильной в обеих группах в течение 12 мес.

Среди пациентов, включенных в исследование ПЕРСПЕКТИВА, преобладающее большинство имело АГ: в группе триметазидина МВ - у 93,5\% и в группе контроля у 93,6 \% больных. На фоне проводимой антигипертензивной терапии (АГТ) в обеих группах через 12 мес отмечено достоверное $(\mathrm{p}<0,0001)$ и одинаковое снижение уровня АД: в группе Предуктал МВ на 11/6,5 мм рт.ст. (до 132/81 мм рт.ст.) и в группе контроля на $10,6 / 6,1$ мм рт.ст. (до 136/84 мм рт.ст.), т. е. до рекомендуемых целевых уровней.

Величина ЧСС, определяемая врачом на визитах больного, достоверно снижалась в обеих группах от исходного к 12 мес: в I группе с 73,5 50,34 до $69,4 \pm 0,34$ уд/мин $(\mathrm{p}<0,0001)$ и во II группе

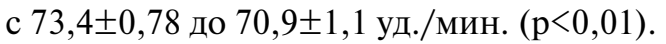

Уменьшение ЧСС при присоединении триметазидина МВ к стандартной терапии подтверждалось данными ЭКГ: через 2 мес с $72 \pm 0,5$ уд/мин до $70 \pm 0,5$ уд/мин $(\mathrm{p}<0,0001)$ и через 12 мес до $69,3 \pm 0,6$ уд/мин., т. е. $-2,7$ уд./мин от исходного, $(\mathrm{p}<0,0001)$ в отличие от больных контрольной группы - (исходно ЧСС $-69 \pm 1,0$ уд/мин и через 12 мес $-69,3 \pm 1,44$ уд/мин).

У больных из группы триметазидина МВ на ЭКГ через 12 мес, обнаружена динамика корригируемого QT интервала в виде его достоверного уменьшения относительно исходного с $0,39 \pm 0,05$ сек до $0,34 \pm 0,14$ сек $(-12,8 \%, p<0,05)$ в отличие от группы контроля. Изменения интервала PQ и ширины комплекса QRS в процессе 12-месячного наблюдения за больными обеих групп отсутствовали.

\section{Оценка изменений параметров ЭхоКГ}

В исследовании ПЕРСПЕКТИВА изучалось влияние стандартной терапии или ее комбинации с триметазидином МВ на показатели ЭхоКГ. Добавление триметазидина МВ к базовой терапии 
Триметазидин МВ
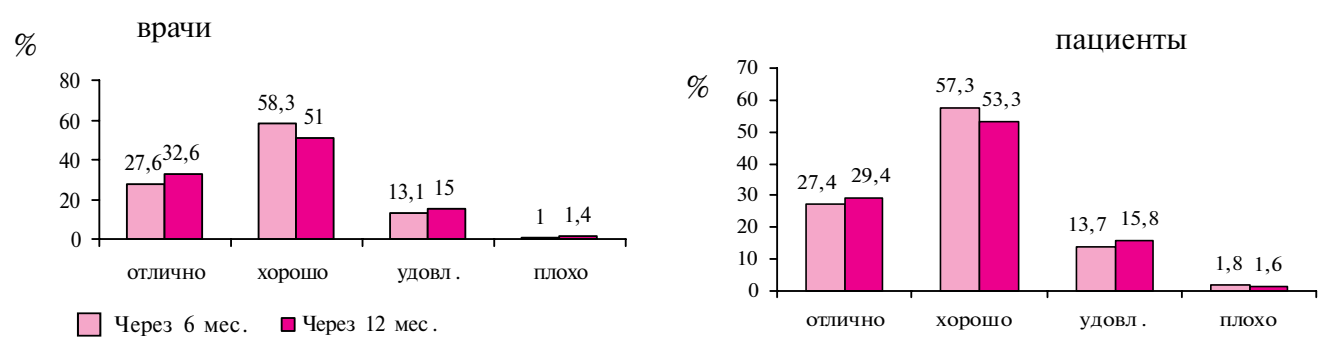

Контроль
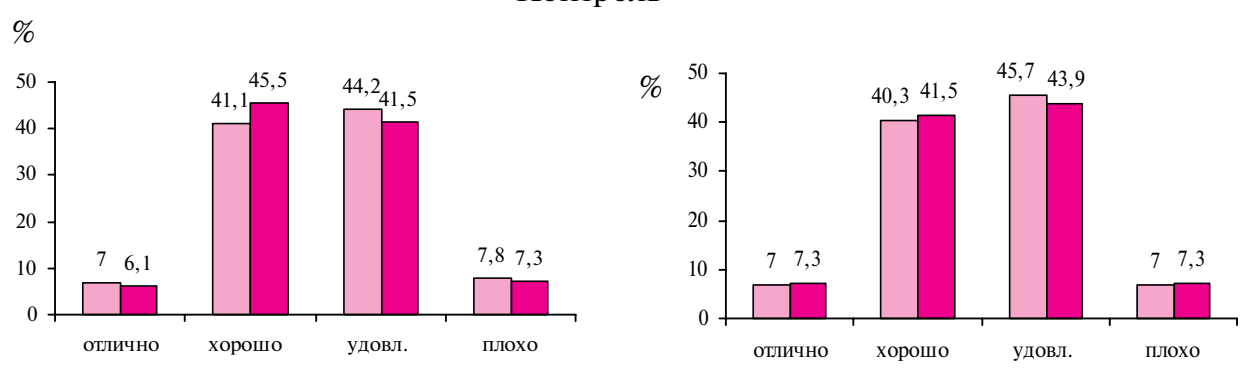

Puc. 3 Эффективность лечения в течение 12 мес больных СтСт, оцениваемая врачом и пациентом (исследование ПЕРСПЕКТИВА).

больных СтСт, сочетающейся с другой патологией, через 6 мес привело к достоверному повышению ФВ ЛЖ на 2,2 \% ( $<<0,001)$, которое сохранялось в последующие мес приема метаболического цитопротектора - через 12 мес повышение ФВ ЛЖ составило $2,4 \%$ от исходного $(\mathrm{p}<0,001)$. В противоположность этому, в контрольной группе изменений ФВ ЛЖ отмечено не было.

Динамики со стороны таких параметров ЭхоКГ как конечный систолический и конечный диастолический размеры, ударный объем в обеих группах отсутствовали.

В тоже время в I группе больных к 12 мес произошло хотя и малое, но достоверное уменьшение толщины межжелудочковой перегородки с $1,19 \pm 0,11$ см до $1,14 \pm 0,12$ см $(-4,2 \%, \mathrm{p}<0,01)$ и задней стенки ЛЖ с $1,13 \pm 0,09$ см до $1,09 \pm 0,11$ см $(-3,5 \%, \mathrm{p}<0,01)$ в отличие от II группы. Следует отметить, что первые достоверные положительные сдвиги со стороны этих показателей были зафиксированы к 6 мес лечения триметазидином MB.

\section{Оценка биохимических параметров}

В обеих группах больных отмечалось достоверное снижение уровня ОХС крови к 12 мес наблюдения: в I группе на $11,2 \%(\mathrm{p}<0,0001)$ и во II группе на $6,9 \%(\mathrm{p}<0,05)$, что может быть обусловлено приемом больными гиполипидемических препаратов.

Концентрация ХС ЛНП в сыворотке крови снижалась в I группе к 6 мес на 13,6 \% (p<0,0001) и оставалось на этом же уровне к 12 мес. Во II группе содержание ХС ЛНП уменьшалось только к 6 мес на $9,2 \%(\mathrm{p}<0,01)$, а к 12 мес возвращалось к исходному значению. Динамика содержания ТГ и ХС ЛВП в сыворотке крови отсутствовали.
С целью оценки безопасности проводимого в течение 12 мес лечения у больных СтСт, сочетающейся с другой патологией и синдромами, исследовался общий анализ крови. В обеих группах не отмечено изменений концентрации гемоглобина. Но выявлено достоверное уменьшение количества лейкоцитов в периферической крови у больных из группы триметазидина MB на $3,2 \%(\mathrm{p}<0,05)$, vs отсутствия их динамики в группе контроля.

Исходно у больных на триметазидине МВ концентрация глюкозы в крови была достоверно выше, чем у больных, получавших только стандартную терапию: $5,73 \pm 0,06$ ммоль/л vs $5,29 \pm 0,11$ ммоль/л $(\mathrm{p}=0,035)$. В процессе лечения триметазидином МВ произошло достоверное $(\mathrm{p}<0,0001)$ снижения уровня глюкозы в крови через 6 мес на 4,8 \% с сохранением этого эффекта к 12 мес. В группе контроля изменения уровня глюкозы в крови отсутствовали.

В процессе лечения и наблюдения за больными оценивались печеночные ферменты. В обеих группах не выявлено динамики уровня АСТ. Что касается АЛТ, то в группе триметазидина МВ наблюдалось даже благоприятное снижение этого фермента с $31,2 \pm 0,87$ ед/л до $27,6 \pm 0,74$ ед/л $(-11,5 \%, \mathrm{p}<0,05)$, тогда как в группе контроля его уровень не изменялся.

Оценка эффективности и переносимости терапии врачами и пациентами

На визитах врачи и больные оценивали эффективность и переносимость проводимой терапии. Установлено, что достоверно большее число врачей и пациентов оценивали эффективность лечения триметазидином МВ в составе стандартной терапии как "отличное" и “хорошее" (рисунок 3). В то же время в группе контроля эффективность базовой терапии врачами и больными чаще оценивалась как 

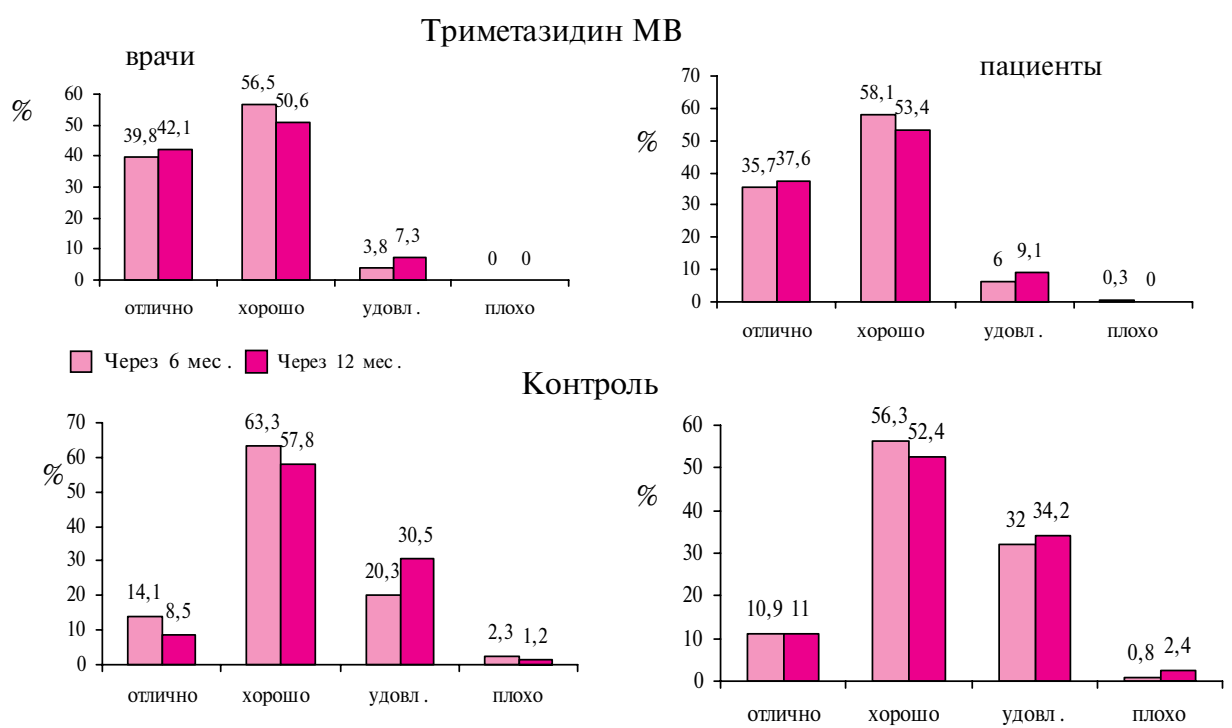

Puc.4 Переносимость лечения в течение 12 мес больных СтСт, оцениваемая врачом и пациентом (исследование ПЕРСПЕКТИВА).

Триметазидин МВ

Контроль
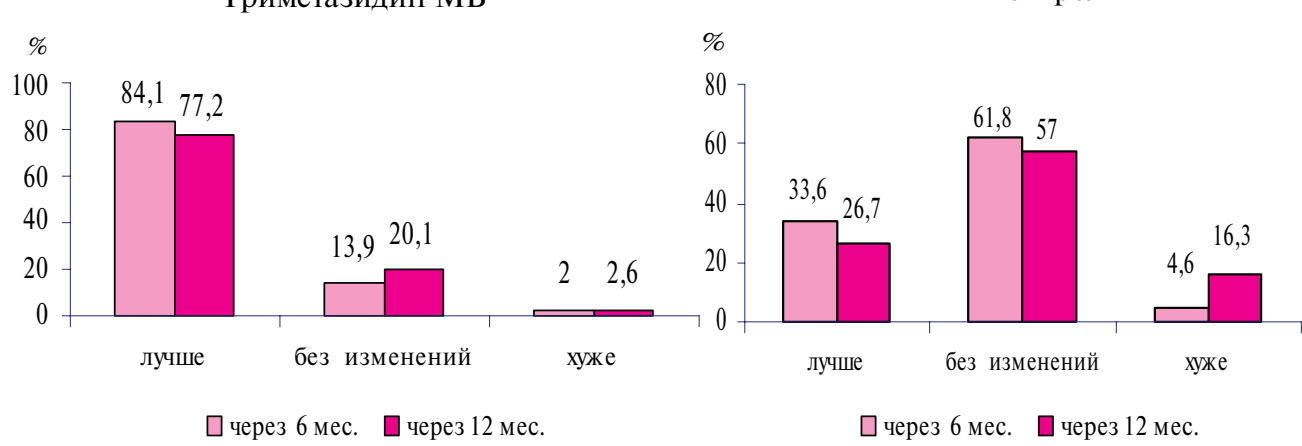

Pис.5 Изменение клинического статуса пациента в процессе наблюдения (исследование ПЕРСПЕКТИВА).

“удовлетворительная" и даже "плохая" и реже как “хорошая", тем более “отличная".

В отношении переносимости лечения в обеих группах прослеживалась такая же разнонаправленная динамика (рисунок 4).

\section{Оценка клинического статуса больного}

Улучшение клинического статуса: сокращение количества приступов стенокардии и таблеток принимаемого Нтг, улучшение общего состояния и течения болезни достоверно чаще (через 6 мес в 2,5 раза и через 12 мес в 2,9 раза) встречалось у больных, принимавших в дополнение к стандартной терапии триметазидин МВ, чем у больных, находившихся только на стандартной терапии (рисунок 5). В контрольной группе, где триметазидин МВ не назначали, клиническое состояние больных практически не изменялось или даже ухудшалось.

Через 12 мес из группы триметазидина МВ были госпитализированы в связи с ухудшением клинического состояния в 2 раза меньше пациентов относительно группы контроля: $13,95 \%$ vs $25,29 \%$, соответственно $(\mathrm{p}=0,007)$.

Любые НЯ, зарегистрированные за 12 мес наблюдения, достоверно реже (в 1,9 раза) встреча- лись у больных, принимавших триметазидин МВ в комплексе с другими гемодинамическими препаратами, чем у пациентов, находившихся только на стандартной терапии: у 7,19\% vs $13,4 \%$, соответственно $(p=0,012)$.

Количество пациентов, имеющих инвалидность на момент включения в исследование, составляло в группе триметазидина МВ + стандартная терапия $-8,28 \%$ и в группе стандартной терапии $-7,03 \%$ $(\mathrm{p}=0,63)$, а к 12 мес $5,7 \%$ vs $12,64 \%$, соответственно $(\mathrm{p}=0,017)$, т.е в 2,2 раза меньше.

\section{Обсуждение}

Результаты многочисленных клинических исследований показали, что комбинация $\beta$-АБ, AK и нитратов не всегда в полной мере обеспечивает оптимальное уменьшение выраженности клинических проявлений стенокардии. Одним из путей расширения возможности консервативной терапии СтСт может быть более активное назначение препарата, действующего непосредственно на метаболические процессы в кардиомиоцитах (КМЦ) и позволяющего достаточно эффективно использовать резервы энергопродукции в условиях дефицита кислорода - три- 
метазидина МВ. Этот препарат селективно ингибирует $\beta$-окисление жирных кислот (ЖК) за счет блокирования последнего из четырех ферментов этого процесса длинноцепочечной 3-кетоацилКоА-тиолазы и тем самым переключает метаболизм ишемизированного миокарда с высокозатратного окисления ЖК на менее кислородозатратный путь окисления глюкозы [6]. Триметазидин МВ препятствует накоплению длиноцепоченных ЖК в митохондриях КМЦ за счет их включения в липиды сарколеммы, увеличивая тем самым синтез мембранных фосфолипидов, тормозит истощение запасов гликогена в сердечной мышце и препятствует накоплению свободных радикалов [7]. Конечным итогом этих процессов является уменьшение внутриклеточного ацидоза, нормализация энергетического метаболизма миокарда и большая устойчивость миокарда к ишемии (уменьшение проявлений ишемии) за счет более рационального использования кислорода.

В клинической части исследования ПЕРСПЕКТИВА продемонстрирована высокая антиангинальная эффективность триметазидина МВ (Предуктала МВ) при добавлении его к стандартной терапии больных СтСт. Это хорошо согласуется с ранее проведенными многочисленными исследованиями [8,9]. Причем степень снижения приступов стенокардии при добавлении триметазидина МВ в исследовании ПЕРСПЕКТИВА хорошо совпадает с выраженностью его антиангинального эффекта, наблюдаемого в других исследованиях, в т. ч. и в Российских, например, в исследовании ТРИУМФ (ТРИметазидин МВ в лечении больных стабильной стенокардией: Уникальный Метаболический эфФект) (n=846 пациентов со СтСт), ПАРАЛЛЕЛЬ (ПрограммА по выявлению пациентов с неэффективной терапией $\beta$-адреноблокаторами и сРАвнитеЛьной оценке эффективности добавЛЕния к терапии триметазидина МВ или изосорбида динитрита при стабиЛьной стенокардии) $(n=903$ пациента со СтСт) [10,11]. Важно отметить, что в исследовании ПЕРСПЕКТИВА высокая ангиангинальная эффективность триметазидина МВ установлена в когорте пациентов СтСт, сочетающейся с такими серьезными заболеваниями как СД-2, ХОБЛ курильщика, ХСН.

Анализ динамики приступов стенокардии в нед четко показал значимое проявление антиангинального эффекта Предуктала МВ ко 2 мес с нарастанием его выраженности по мере увеличения длительности лечения. На стандартной терапии (группа контроля) появление положительных антиангинальных сдвигов, при их меньшей степени выраженности, было отсрочено до 6 мес с отсутствием дальнейшего прироста к 12 мес наблюдения. Аналогично этому прослежи- валась и динамика потребления таблеток НТГ для купирования приступов стенокардии. Очевидно, что комбинация триметазидина МВ с другими кардиологическими препаратами гемодинамического действия (нитраты, $\beta$-АБ, АК) обеспечивала больший по выраженности и продолжительности антиангинальный эффект у больных с сочетанной патологией.

В представленном исследовании ПЕРСПЕКТИВА, как и в ряде других, убедительно продемонстрирована отличительная особенность действия триметазидина МВ, связанная с нарастанием его клинического (антиангинального/антиишемического) эффекта с течением времени [11-13]. Этот факт дает основание для непрерывного (в течение продолжительного периода времени) применения терапии, регулирующей метаболизм миокарда, а именно триметазидина МВ в составе стандартной терапии СтСт, в т. ч. у больных с ХСН, СД-2 и ХОБЛ. Более активное назначение триметазидина МВ больным СтСт может определенно уменьшить применение пролонгированных нитратов (надо помнить о развитии синдрома толерантности к нитратам и о целесообразности использования нитратов только в случае реальной необходимости) и усилить противоишемическую активность препаратов с гемодинамическим действием ( $\beta-A Б, A K)$.

Одним из важнейших критериев эффективности лечения антиангинальными препаратами является уменьшение ФК стенокардии; в идеале - это перевод больных СтСт в I ФК, ассоциированный с высокой толерантностью к физической нагрузке. В исследовании ПЕРСПЕКТИВА наглядно продемонстрировано уменьшение тяжести эпизодов стенокардии на фоне добавления Предуктала МВ к стандартной терапии больных СтСт (семикратный рост количества больных c I ФК), в отличие от группы контроля.

В последнее время появились факты возможного положительного влияния триметазидина МВ на дисперсию QT [14]. Известно, что удлинение интервала QT рассматривается как предиктор фатальных нарушений ритма. Приобретенная форма удлинения QT может возникать при разных причинах: при острой ишемии, атеросклеротическом или постинфарктном атеросклерозе, приеме некоторых лекарственных средств. В исследовании ПЕРСПЕКТИВА только в группе больных, принимавших в составе стандартной терапии триметазидин МВ, было обнаружено достоверное уменьшение корригируемого QT интервала. Следует отметить, что данный эффект в настоящем исследовании при СтСт проявился только при длительном (не менее 12 мес) приеме триметазидина МВ.

Полученные в исследовании ПЕРСПЕКТИВА результаты подтверждают возможность улучшения 
сократительной функции сердца под влиянием терапии триметазидином МВ. По данным литературы это действие препарата более заметно при исходно низкой ФВ ЛЖ (в настоящее исследование включали больных с ФВ ЛЖ > 40 \%) [15-17]. Такое положительное действие триметазидина МВ объясняют несколькими механизмами. Во-первых, традиционным ингибированием данным препаратом $\beta$-окисления (ЖК) на фоне увеличения активности пируватдегидрогеназы и усиления окисления глюкозы, а во-вторых, его способностью увеличивать соотношение креатинфосфата к аденозинтрифосфату (АТФ), предотвращать внутриклеточный ацидоз и повреждение клеток, снижая образование свободных активных форм кислорода, а также подавлять апоптоз клеток и уменьшать перегрузку клетки ионами кальция [18-20]. Сравнительно недавно установлено, что триметазидин МВ может подавлять вос паление и развитие фиброза миокарда через снижение образования свободных радикалов кислорода (известно, что они стимулируют рост гладкомышечных клеток и отложение коллагена) и фактора роста соединительной ткани [20-21]. В совокупности все эти эффекты триметазидина МВ приводят к уменьшению повреждения клеток, к обратному ремоделированию миокарда и улучшению сократительной функции сердца. Экспериментальные данные демонстрируют определенное снижение степени гипертрофии миокарда, индуцированной действием адреналина, при использовании триметазидина МВ. Возможно, вышеперечисленные процессы при применении триметазидина МВ лежат в основе выявленного в исследовании ПЕРСПЕКТИВА факта некоторого уменьшения толщины стенок ЛЖ (хотя, это требует дальнейшего изучения).

Поскольку достоверное улучшение сократительной функции сердца на фоне триметазидина МВ как в исследовании ПЕРСПЕКТИВА, так и в других исследованиях, происходит к 6 мес терапии, то это еще один весомый аргумент в пользу длительного приема препарата.

В экспериментальных исследованиях были продемонстрированы потенциальные противовоспалительные эффекты триметазидина МВ. Триметазидин МВ в 3 раза уменьшал скорость проникновения нейтрофильных гранулоцитов в миокард после острой ишемии и реперфузии [22]. Di Napoli P, et al. у больных ишемической дилатационной кардиомиопатией (КМП) обнаружили повышение С-реактивного белка (СРБ) на фоне приема триметазидина в отличие от группы контроля, где отмечен его рост [23]. В другом исследовании у больных СД-2 с ишемической КМП достоверное снижение концентрации СРБ на $38 \%$ выявлялось после 3-месячной терапии триметазидином [24]. В исследовании ПЕРСПЕКТИВА обнаружено снижение количес- тва лейкоцитов в периферической крови на фоне лечения триметазидином МВ. Очевидно, это можно рассматривать как одно из проявлений противовоспалительного эффекта триметазидина МВ у больных СтСт, сочетающейся СД-2, ХОБЛ, $\mathrm{XCH,} \mathrm{т.} \mathrm{е.} \mathrm{с} \mathrm{заболеваниями} \mathrm{и} \mathrm{синдромами,} \mathrm{при}$ которых процессы воспаления активируются, а степень иммунной активности сопряжена с выраженностью патологии и прогнозом.

Обнаруженное в исследовании ПЕРСПЕКТИВА снижение уровня глюкозы в крови натощак у больных, принимавших триметазидин МВ, согласуется с результатами других исследований [25]. Триметазидин МВ, ингибируя окисление ЖК, стимулирует общие процессы утилизации глюкозы, включая гликолиз и окисление глюкозы.

Длительный прием триметазидина МВ в составе стандартной терапии больных СтСт не влиял на уровень печеночных ферментов. В целом переносимость триметазидина МВ в составе стандартной терапии была хорошей.

Добавление триметазидина МВ к стандартной терапии при СтСт сопровождалось улучшением клинического состояния больных: их в 2 раза реже госпитализировали в течение годичного наблюдения, и они реже переходили на инвалидность по сравнению с больными, получавшими только стандартную терапию.

\section{Заключение}

Результаты Российского исследования ПЕРСПЕКТИВА, изучавшего клиническую эффективность и безопасность терапии Предукталом МВ в комплексе с оптимальной стандартной терапией при СтСт, сочетающейся с СД-2, ХОБЛ, ХСН, продемонстрировали, что дополнительное назначение триметазидина МВ: представляет собой ценную стратегию уменьшения приступов и тяжести стенокардии, улучшения функции ЛЖ; сопровождается благоприятным снижением концентрации глюкозы крови и возможным противовоспалительным эффектом (уменьшение количества лейкоцитов в периферической крови).

Итогом такого комплексного действия триметазидина МВ служит благоприятное влияние на общий функциональный и клинический статусы больного, так и на отдаленный прогноз (в течение года).

Таким образом, результаты Российского многоцентрового проспективного исследования ПЕРСПЕКТИВА указывают на целесообразность более активного применения метаболической терапии в виде Предуктала МВ в клинической практике врача у больных СтСт, в т.ч. страдающих сочетанной патологией: ХСН, СД-2 или ХОБЛ курильщика. 


\section{Список литературы}

1. Диагностика и лечение стабильной стенокардии Российские рекомендации (второй пересмотр) 2008 г.

2. Бубнова М.Г., Аронов Д.М., Оганов Р.Г., Рудоманов О.Г., Путылина А.С. (от имени исследователей). Клиническая характеристика и общие подходы к лечению пациентов со стабильной стенокардией в реальной практике. Российское исследование “ПЕРСПЕКТИВА" (часть I). Кардиоваскулярная терапия и профилактика, 2010; 6: 47-56.

3. Eastaugh JL, Calvert MJ, Freemantle N Highlighting the need for better patient care in stable angina: results of the international Angina Treatment Patterns (ATP) Survey in 7074 patients. Family Practice 2005; 22: 43-50.

4. Оганов Р.Г., Лепахин В.К., Фитилев С.Б., Левин А.М., Титарова Ю.Ю., Сычев Е.Н.Особенности диагностики и терапии стабильной стенокардии в Российской Федерации (международное исследование АTP -Angina Treatment Pattern).Кардиология 2003; 5: 9-15.

5. Fox K, Garcia MAA, Ardissino D et al Guidelines on the management of stable angina pectoris: executive summary. The Task Force on the Management of Stable Angina Pectoris of the European Society of Cardiology. Eur Heart J 2006; 27: 1334-81.

6. Kantor P.E., Lucien A. Kozar R, Lopaschuk GD. The antianginal drug trimetazidine shifts cardiac metabolism from fatty acid oxidation to glucose oxidation by inhibiting mitochondrial long-chain 3-ketoacyl coenzyme A thiolase. Circ Res 2000; 86: 580-8.

7. Stremmel W, Pohl L, Ring A, Herrmann T. A new concept of cellular uptake and intracellular trafficking of long-chain fatty acids. Lipids 2001; 36: 981-9.

8. Marzilli M, Klein WW. Efficacy and tolerability of trimetazidine in stable angina: a meta-analysis of randomized double-blind, controlled trials Coronary Artery Disease 2003; 14: 171-9.

9. Szwed H., SadovskyZ., Elikovsky W.et.al. Combination treatment in stable effort angina using trimetazidine and metoprolol: results of a randomized, double-blind, multicentre study (TRIMPOL II). TRImetazidine in POLand. Eur.Heart J 2001; 22: 2267-74.

10. Маколкин В.И., Осадчий К.К. Эффективность и переносимость триметазидина при лечении стабильной стенокардии напряжения в течение 8 недель (российское исследование ТРИУМФ) Кардиология 2003; 43 (6): 18-22.

11. Оганов Р.Г., Глезер М.Г., Деев А.Д. от имени исследователей. Результаты Российского исследования ПАРАЛЛЕЛЬ: Программа выявления пациентов с неэффективной терапией бета-адреноблокаторами и сравнительной оценки эффективности добавления к терапии Предуктала МВ или изосорбида динитрата при стабильной стенокардии. Кардиология, 2007; 3: 4-13.

12. Аронов Д.М., Тартаковский Л.Б., Новикова Н.К. и др.
Сравнительная оценка влияния физических тренировок и триметазидина. Кардиоваск тер и проф 2002; 32-40.

13. Глезер М.Г., Новикова М.В., Киселева И.В., Сайгитов Р.Т. Сравнительная оценка эффективности присоединения к терапии $\beta$-адреноблокаторами пролонгированной формы триметазидина или изосорбида динитрата у пациентов со стабильной стенокардией. Кардиоваск тер и проф 2006; 4: 57-64.

14. Глезер М.Г., Васильев С.В. Антиангинальная и противошемическая эффективность триметазидина с модифицированным высвобождением у пациентов с нестабильной стенокардией. Кардиоваск тер и проф 2008; 8: 42-6.

15. Vitale C, Wajngaten M, Sposato B. et al. Trimetazidine improves left ventricular function and quality of life in elderly patients with coronary artery disease. Eur Heart J 2004; 25: 1814-21.

16. Rosano GM, Vitale C, Sposato B. et al. Trimetazidine improves left ventricular function in diabetic patients with coronary artery disease: a double-blind placebo-controlled study. Cardiovasc Diabetol 2003; 2: 16.

17. Di Napoli P., Di Giovanni P., Gaeta M.A. et.al. Trimetazidine and reduction in mortality and hospitalization in patients with ischemic dilated cardiomyopathy: a post hoc analysis of the Villa Pini d'Abruszzo TrimetazidineTrial. J Cardiovasc Pharmacol 2007; 50: 585-9.

18. Gao D, Ning N, Niu X et al. Trimetazidine: a meta-analysis of randomized controlled trial in heart failure. Heart 2010; doi:10.1136/2010.208751.

19. Di Napoli P, Taccardi AA. Trimetazidine: the future of cardiac function? Future Cardiol 2009; 5: 421-4.

20. Bertomeu-Gonzalez V, Bouzas-Mosquera A, Kaski JC. Role of trimetazidine in management of ischemic cardiomyopathy. Am J Cardiol 2006; 98:19J-24.

21. Lui X, Gai Y, Lui $F$ et.al. Trimetazidine inhibits pressure overload-induced cardiac fibrosis through NADPH oxidaseROS-CTGF pathway. Cardiovasc Res 2010; 88: 150-8.

22. Williams FM, Tanda K, Kus M et al. Trimetazidine inhibits neutrophil accumulation after myocardial ischemia and reperfusion in rabbits. J Cardiovasc Pharmacol. 1993; 22: 82833.

23. Di Napoli P., Taccardi AA., Barsotti A Long term cardioprotective action of trimetazidine and potential effect on the inflammatory process in patients with ischaemic dilated cardiomyopathy. Heart 2005; 91: 161-5.

24. Belardinelli R., Cianci G, Gigli M et al. Effect trimetazidine on myocardial reperfusion and left ventricular systolic function in type 2 diabetic patients with ischemic cardiomyopathy. J Cardiovasc Pharmacol 2008; 51: 611-5.

25. Fragasso G, Piatti PM, Monti L. et al. Short- and long-term beneficial effects of trimetazidine in patients with diabetes and ischemic cardiomyopathy. Am Heart J 2003; 146:18-25.

\section{**СПисок врачей-участников исследования ПЕРСПЕКТИВА.}

Гулина М.С., Ермолович А.П., Кошелева И.П., Маякова А.Ф., Молокова Е.С. (Архангельск); Алейникова Л.П., Гусейнова Е.А., Жданова Н.Н., Капшук Г.В., Фомина Т.В., Хмара А.С., Шешина В.Г., Шмакова Н.Н. (Белгород); Богдашова В.Н., Голотина Е.А., Федоренко О.А.(Брянск); Гич О.В., Ереткова Т.М., Швецова И.И. (Владивосток); Барсегян А.А., Кириченко Е.А., Кочнева Л.И., Пашкова Е.В. (Волгоград); Анисимова Н.Ю., Васютина Л.Н., Крысанова Н.Н., Кудинова Л.Е., Лазарева Е.И., Михеева Е.С., Свиридова Л.А., Соколова Р.А., Худякова Т.С. (Воронеж); Брылина Л.А., Подкопьева Е.Н., Поспелова Н.В., Ступакова Т.Ф.(Екатеринбург); Зайцева Е.Б., Старцева Э.И. (Иваново); Гумарова Т.Н., Зарецкий В.В., Коровкина С. А. (Ижевск); Кошкина Ю.В.(Иркутск); Белова Г.И., Дылевская Е. П., Нурлыев А.Ф. (Казань); Беринова М.М., Кошелева О.В., Стрелина Т.И. (Самара); Федотова Г.В. (Кемерово); Архипова Ю.В., Власова О.Б., Диденко Л.А., Иорданиди Е.В., Кучерявая Т.Ю., Самоненко Л.П., Строганов В.В., Шевченко Е.А. (Краснодар); Самбоская А.Г., Хлебодаров Ф.Е.(Курск); Самойленко Т.В. (Липецк); Абу-Альджадаель М.М., Андреева Т.В., Андриенко Т.П., Берестенникова А.В. Богомолова Е.А., Босякова Н.А., Ветлучина З.В., Вишневская М.С., Возисов А.С., Гвоздева С.В., Гинькова В.В., Дорошкова Н.Г., 
Завьялова Л.А., Зайцева О.В., Зеленова Т.И., Иващенко Т.Н., Ильинова О.Ю., Казакова И.Ю., Калмыкова К.В., Кондратьева Н.В., Королёва Н.М., Литвинова И.А., Люцкая В.В., Одноралова Н.Д., Орловский О.И., Подгородетская Н.В., Попова Т.А., Сумм Ю.Н., Туровцева Е.П., Уварова Н.Н., Фрелих Н.М., Хартова Н.В., Хребтова О.Г., Цветкова И.Н., Целых Е.А., Черникова И.В., Шахмаганова М.В., Шелегедо Е.Ю., Шелковая Н.А., Шестакова Г.Н., Яковлева Т.В. (Москва); Борунова В.А., Иваненкова Н.Ю., Кондратьева Н.А., Сусликов А.В.(Московская область); Морозов А.В. (Набережные Челны); Давыдова Н.А, Зеленова Т.Г., Королёва В.В., Мингалева С.В., Смирнова Л.Е. (Н.-Новгород); Кириллова Е.В., Коблякова И.И., Кондрацкая О.В. (Новокузнецк); Кузнецова Е.А., Щербакова М.Г.; Аникина Т.В., Васильева Е.В., Махортова И.В., Никитенко С.А., Сдобнова О.С., Титова Н.Л. (Новосибирск); Субботина Р.И., Черникова Л.С., Ясакова Е.В. (Оренбург); Старшинова А.Ю. (Пенза); Геворкян А.Б., Гилева И.Н., Едигарова О.Г., Некрасова И.В., Тимошенко О.В. (Пятигорск); Волкова Е.М., Гайбарян С.Х., Карноушенко Т.М., Корякина Т.Л., Курганская Н.И., Передернин С.А. (Ростов-на-Дону); Сидорчук Л. А. (Рязань); Андреева Д.В., Боковин Н.А., Головина Т.С., Каипова Н. А., Калинина Л.В., Козупеев Ю.А., Коростовцева Г.Л., Кривошеева Н.Н., Кузнецова В.В., Нелюбина Е.С., Павлова Ю.В., Панчишных И.Н., Панюшина О.В., Пепелышева Т.А., Потапова И.В., Рыбинская В.С., Савин М.А., Слухаенко С.А., Слюсар Н.М., Софин А.Б., Ступникова Н.К., Шабанова И.М., Шамгунова С.Л., Юшкова Л.В. (Санкт-Петербург); Радченко Е. Г., Семенова Е.Г., Трубицина Ю.И., Трусилкина В.Н., Чернышова Н.В. (Ставрополь); Царёва Т.В. (Тверь); Харитонова О.А.(Томск); Новикова О.А., Серёгин Д.В., Шестова И.И. (Тула); Гончарова М.Ф., Латышев Д.А., Непочатых Л.И. (Тюмень); Грицань Т.С., Королева Р.Л., Кулакова О.Г., Смоктунова Н.Г. (Хабаровск); Бикташева А.З., Бикчетаева А.З., Дмитриева В.В., Зайнуллин М. Г., Ибрагимова Р.И., Магадиева Г.М., Мухамадиярова Н.М., Пилюшина Р.Р. (Уфа); Баранова М.В., Каляганова И.Ю., Сейранян Т.В., Смирнова Е.Ю. (Ярославль). 